\title{
Optimism and the Socioeconomic Status Gradient in Adolescent Adiposity
}

\section{Citation}

Khullar, Dhruv, Nicolas M. Oreskovic, James M. Perrin, and Elizabeth Goodman. 2011. "Optimism and the Socioeconomic Status Gradient in Adolescent Adiposity." Journal of Adolescent Health 49 (5) (November): 553-555. doi:10.1016/j.jadohealth.2011.04.003.

\section{Published Version}

doi:10.1016/j.jadohealth.2011.04.003

\section{Permanent link}

http://nrs.harvard.edu/urn-3:HUL.InstRepos:30207925

\section{Terms of Use}

This article was downloaded from Harvard University's DASH repository, and is made available under the terms and conditions applicable to Other Posted Material, as set forth at http:// nrs.harvard.edu/urn-3:HUL.InstRepos:dash.current.terms-of-use\#LAA

\section{Share Your Story}

The Harvard community has made this article openly available.

Please share how this access benefits you. Submit a story.

\section{Accessibility}




\title{
Optimism and the SES Gradient in Adolescent Adiposity
}

\author{
Dhruv Khullar, BA ${ }^{1}$, Nicolas M. Oreskovic, MD, MPH², James M. Perrin, MD², and Elizabeth \\ Goodman, MD² \\ ${ }^{1}$ Yale School of Medicine, New Haven, CT \\ ${ }^{2}$ Center for Child and Adolescent Health Policy, MassGeneral Hospital for Children, Boston, MA
}

\begin{abstract}
Purpose-To assess if dispositional optimism is associated with adiposity and explore if dispositional optimism mediates the relationship between parent education and adiposity (BMI z score).

Methods-Multivariable regression analyses of data collected from 1298 non-Hispanic black and white 12-19 year olds from a single Midwestern public school district.

Results-Less optimistic adolescents had higher BMI z scores $(r=-0.09, \mathrm{p}<0.001)$. Addition of dispositional optimism to the regression model caused an approximately $10 \%$ attenuation of the parent education and BMI z score relationship. Sobel tests confirmed that this attenuation indicated partial mediation.
\end{abstract}

Conclusion-Lower dispositional optimism is associated with higher adiposity and this association accounts for some of the influence of parent education on adolescent adiposity.

\section{Keywords}

Socioeconomic status; disparities; dispositional optimism; body mass index; adiposity

\section{Introduction}

Adolescents and adults from households with lower socioeconomic status (SES) have higher rates of obesity [1]. There is a growing body of evidence that suggests psychological factors play a role in the development of obesity. Thus, psychological factors may partially underlie the SES gradient in adolescent obesity. One such psychological trait is dispositional optimism, the tendency to expect positive outcomes and believe good things will happen in life, hereafter referred to as "optimism" [2]. Studies, mostly in adults, suggest that optimism is associated with several health outcomes, including some linked to obesity [3, 4]. Fewer studies have explored the optimism-health link in adolescence [5] or its relationship to health disparities, although lower SES youth have been shown to be less optimistic [6]. This study extends prior work by exploring the relationship between optimism and adiposity and assessing if optimism mediates the established SES-adiposity relationship.

(C2011 Society for Adolescent Medicine. Published by Elsevier Inc. All rights reserved.

Correspondence and reprint requests to: Elizabeth Goodman, MD, Center for Child and Adolescent Health Policy, MassGeneral Hospital for Children, 50 Staniford Street, Suite 901, Boston, MA 02114; phone: 617-643-6631 ; fax: 617.726.1886; egoodman3@partners.org.

Publisher's Disclaimer: This is a PDF file of an unedited manuscript that has been accepted for publication. As a service to our customers we are providing this early version of the manuscript. The manuscript will undergo copyediting, typesetting, and review of the resulting proof before it is published in its final citable form. Please note that during the production process errors may be discovered which could affect the content, and all legal disclaimers that apply to the journal pertain. 


\section{Methods}

\section{Study Sample}

This cross-sectional study utilizes data from 1298 non-Hispanic black and white participants in the PSD Study, a longitudinal cohort study in the greater Cincinnati area. Inclusion criteria were baseline (2001-2002 school year) information on optimism, height, weight, and parent education [6]. The Institutional Review Boards at the participating university and local children's hospital approved all study procedures. Optimism was assessed using the Life Orientation Test (LOT), a scale validated for use in adolescents[7]. Parent education as reported by a parent/guardian, a measure less dynamic than income, was used to indicate SES. Analysis categories were: high school or less, some college or vocational training, college graduate, and professional degree. Professional degree was used as the reference group in regression models. Measured height and weight were used to calculate BMI (kg/ $\mathrm{m}^{2}$ )[1]. BMI z-scores were derived from Centers for Disease Control and Prevention growth chart standards and used in analyses. Obesity was defined as a BMI-for-age $>=95 \%$, and overweight as BMI-for-age $>=85 \%$ but less than the $95 \%$. Pubertal status (prepubertal, peripubertal, postpubertal) was assessed according to a validated protocol [8]. Date of birth, gender, and parent-identified race/ethnicity were abstracted from school district administrative data.

\section{Statistical Analysis}

Prior work established the relationships between SES and optimism and SES on adiposity $[1,6]$. To evaluate whether optimism is associated with adiposity and whether optimism mediates the SES-adiposity relationship, we performed bivariate analyses (correlational, ANOVA) and multivariable linear regression analyses adjusted for age, sex, race, and pubertal status. Sobel testing confirmed whether the difference in the regression coefficients for parent education without and with optimism in the model represented mediation. Analyses were performed using PASW Statistics 18, Release Version 18.0 (@ SPSS, Inc., 2009, Chicago, IL, www.spss.com) except for the Sobel tests, which were performed using an interactive online mediation test calculator [9]. Means are presented with standard deviation (SD).

\section{Results}

Table 1 presents the demographics of the study sample. Less optimistic adolescents had higher BMI z-scores $(\mathrm{r}=-0.09, \mathrm{p}<0.001)$ and optimism was lower among overweight and lowest for obese youth $\left(\mu_{\text {obese }}=18.4(\mathrm{SD} 3.9), \mu_{\text {overweight }}=1837\right.$ (3.7) $\mu_{\text {normal weight }}=19.3(3.9)$, $\mathrm{p}=0.002$ ) compared to normal weight youth. In multivariable regression analysis, the inverse association between optimism and BMI-z score remained after adjusting for covariates ( $\beta=$ $-002, \mathrm{p}<.01)$.

To test if optimism mediated the SES-adiposity relationship, we verified the association between parent education and both optimism and adiposity established in prior studies [1,6]. Adolescents from households with lower parent education were less optimistic than adolescents from households with professional degrees, and this relationship followed a graded pattern (high school or less $[\beta=-1.13, p<0.001]$, some college $[\beta=-0.90, p$ $<0.001]$ ), college graduates $(\beta=-0.25$, NS). Likewise, youth from families with highly educated parent(s) had lower BMI z-scores. We then assessed the change in coefficients for parent education with optimism in the regression model. The figure presents the regression results without and with optimism in the model. Sobel testing revealed that the differences in regression coefficients between these two models were significant for the lower two 
education categories (high school or less $\mathrm{p}=0.019$, some college $\mathrm{p}=0.029$, college graduates $\mathrm{p}=0.38$ ).

\section{Discussion}

This study demonstrates that optimism, a psychological trait, is inversely associated with adolescent adiposity and that optimism partially mediates the lower parent education-greater adiposity relationship. Adolescents from households with lower parent education tend to be less optimistic and this lower degree of optimism explains some of the disparity in BMI. Furthermore, these data suggest that having a parent with a college degree or higher may be a threshold for conferring a protective effect in terms of adolescent optimism and adiposity.

By demonstrating that optimism is one path through which SES may exercise its influence on adiposity, this study makes an important contribution to the growing literature on social inequalities and health. Adolescent adiposity predicts the risk of becoming obese and developing cardiovascular disease as an adult [10]. By demonstrating an association between lower optimism and increased adiposity in adolescence, this study suggests that lower optimism may be one pathway through which these negative health outcomes manifest later in life.

This study has several limitations. Analyses were cross-sectional, so we cannot infer causality. However, parent education is generally static and temporally precedes the development of optimism and obesity. Similarly, because optimism is a trait that develops early in life[2], it likely also precedes the development of adolescent adiposity. Parent education was the single measure of SES. A different marker, such as income, may show different results. Finally, this sample is from a single predominantly non-Hispanic black and white Midwestern school district. These findings may not generalize to other populations. Nonetheless, this sample has important strengths; it was a large, socioeconomically diverse, gender-balanced, community-based cohort with measured information on adiposity. Future work with geographically and ethnically diverse samples may increase generalizability.

\section{Implications and Contributions}

By evaluating the mediating role of optimism in the relationship between parent education and adolescent adiposity, this study provides support for the mind-body link as a contributor to the development of health disparities and highlights the importance of looking beyond physical environmental and behavioral factors in the genesis of health disparities.

\section{Acknowledgments}

Funding Sources: Supported by NIH grants HD041527 and T35-HD007446.

\section{References}

1. Goodman E, Adler NE, Daniels SR, et al. Impact of objective and subjective social status on obesity in a biracial cohort of adolescents. Obes Res. 2003; 11(8):1018-1026. [PubMed: 12917508]

2. Scheier MF, Carver CS, Bridges MW. Distinguishing optimism from neuroticism (and trait anxiety, self-mastery, and self-esteem): a reevaluation of the Life Orientation Test. J Pers Soc Psychol. 1994; 67(6):1063-1078. [PubMed: 7815302]

3. Matthews KA, Raikkonen K, Sutton-Tyrrell K, et al. Optimistic attitudes protect against progression of carotid atherosclerosis in healthy middle-aged women. Psychosom Med. 2004; 66(5):640-644. [PubMed: 15385685]

4. Scheier MF, Matthews KA, Owens JF, et al. Optimism and rehospitalization after coronary artery bypass graft surgery. Arch Intern Med. 1999; 159(8):829-835. [PubMed: 10219928] 
5. Mannix MM, Feldman JM, Moody K. Optimism and health-related quality of life in adolescents with cancer. Child Care Health Dev. 2009; 35(4):482-488. [PubMed: 19196249]

6. Finkelstein DM, Kubzansky LD, Capitman J, et al. Socioeconomic differences in adolescent stress: the role of psychological resources. J Adolesc Health. 2007; 40(2):127-134. [PubMed: 17259052]

7. Goodman EKJ, DuRant RH. Use of the Life Optimism Test among adolescents in a clinical setting: A report of reliability testing. J Adolesc Health. 1997; 21:218-220. [PubMed: 9304451]

8. Dolan LM, Bean J, D'Alessio D, et al. Frequency of abnormal carbohydrate metabolism and diabetes in a population-based screening of adolescents. J Pediatr. 2005; 146(6):751-758. [PubMed: 15973311]

9. Preacher KJ, Leonardelli JJ. An interactive mediation tool for mediation tests. 2003 Available from: http://peoplekuedu/ preacher/sobel/sobelhtm.

10. Franks PW, Hanson RL, Knowler WC, et al. Childhood obesity, other cardiovascular risk factors, and premature death. N Engl J Med. 2010; 362(6):485-493. [PubMed: 20147714] 


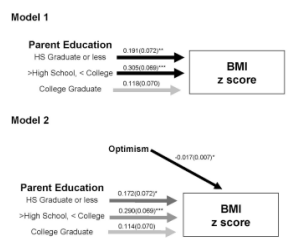

Figure.

Results of multivariable regression analyses used in testing for mediation for the SESadiposity relationship by optimism $(\mathrm{N}=1298)$. B $(\mathrm{SE})$ are presented along the relevant paths. Model 1 tested the association of parent education adjusting for age, race/ethnicity, sex and pubertal status. Model 2 added optimism to the regression model. Model 1 Adjusted $\mathrm{R}^{2}=0.048$. Model 2 Adjusted $\mathrm{R}^{2}=0.051 . * \mathrm{P}<.05, * * \mathrm{P}<.01, * * * \mathrm{P}<.001$ 
Table 1

Description of the Study Sample $(\mathrm{N}=1298)$

\begin{tabular}{|c|c|c|}
\hline & $\mathbf{N}$ & $\%$ \\
\hline \multicolumn{3}{|l|}{ Gender } \\
\hline Male & 636 & 49.0 \\
\hline Female & 662 & 51.0 \\
\hline \multicolumn{3}{|l|}{ Race } \\
\hline White & 691 & 53.2 \\
\hline Black & 607 & 46.8 \\
\hline \multicolumn{3}{|l|}{ Pubertal Status } \\
\hline Prepubertal & 29 & 2.2 \\
\hline Peripubertal & 428 & 33.0 \\
\hline Postpubertal & 839 & 64.6 \\
\hline Missing & 2 & 0.2 \\
\hline \multicolumn{3}{|l|}{ Parent Education } \\
\hline High School or less & 319 & 24.6 \\
\hline$>$ High School, < college & 370 & 28.5 \\
\hline College Graduate & 339 & 26.1 \\
\hline Professional Degree & 270 & 20.8 \\
\hline \multicolumn{3}{|l|}{ Weight Status } \\
\hline Normal Weight & 780 & 60.1 \\
\hline Overweight & 251 & 19.3 \\
\hline \multirow[t]{2}{*}{ Obese } & 267 & 20.6 \\
\hline & Mean & Standard Deviation \\
\hline Age & 15.24 & 1.66 \\
\hline Optimism & 19.01 & 3.87 \\
\hline BMI z score & .74 & 1.02 \\
\hline
\end{tabular}

